\title{
Case series of reports of pruritus and sipuleucel-T submitted to the Food and Drug Administration Adverse Event Reporting System
}

\author{
Graça M. Dores ${ }^{1 *}$ (D, Silvia Perez-Vilar ${ }^{1,2}$ and Manette T. Niu ${ }^{1}$
}

\begin{abstract}
Sipuleucel-T, an autologous active cellular immunotherapy, is indicated for the treatment of asymptomatic or minimally symptomatic castration-resistant prostate cancer. The U.S. Food and Drug Administration Adverse Event Reporting System (FAERS) received a report of pruritus without rash following the second dose of sipuleucel-T in a patient who had otherwise not started any new medications concurrent with the first and second doses of sipuleucel-T. No further sipuleucel-T was administered, but symptoms persisted for at least 6 weeks despite treatment with several medications aimed at symptomatic relief of pruritus. Rash is the only dermatologic adverse event included in the sipuleucel-T U.S. package insert. A search of the FAERS database yielded seven additional U.S. reports of pruritus and sipuleucel-T identified as the primary suspect medication; two of these occurred prior to the administration of sipuleucel-T (following leukapheresis). In data mining analyses, pruritus following sipuleucel-T was not reported more frequently than expected when compared to all other adverse event-drug/biologic combinations in FAERS. Thus, pruritus following sipuleucel-T administration was rarely, but not disproportionately, reported to FAERS. Although we cannot exclude the possibility that diabetes, malignancy, or other conditions may have contributed to pruritus in our index patient, in view of the timing of sipuleucel- $T$ therapy and onset of symptoms, a drug/biologic-related reaction is plausible. In the appropriate clinical scenario, sipuleucel-T (or its components) should not be overlooked as a potential etiological agent in pruritus.
\end{abstract}

Keywords: Sipuleucel-T, Provenge, Pruritus, Castration-resistant, Adverse events, FAERS

\section{Background}

On April 29, 2010, the U.S. Food and Drug Administration approved sipuleucel-T (Provenge, Dendreon Corporation), the first therapeutic cancer vaccine [1]. This autologous active cellular immunotherapy is indicated for the treatment of asymptomatic or minimally symptomatic metastatic castration-resistant prostate cancer [2]. Peripheral blood mononuclear cells are collected from the patient through leukapheresis; thereafter, antigen-presenting cells are harvested ex vivo, exposed to prostatic acid phosphatase fused to granulocyte-macrophage colony-stimulating factor

\footnotetext{
* Correspondence: graca.dores@fda.hhs.gov

${ }^{1}$ Division of Epidemiology, Office of Biostatistics and Epidemiology, Center for Biologics Evaluation and Research, U.S. Food and Drug Administration, 10903 New Hampshire Avenue, Silver Spring, MD 20993-0002, USA Full list of author information is available at the end of the article
}

(GM-CSF), and infused back into the patient [2]. In vivo, a T-cell-mediated immune response against prostate cancer cells expressing prostatic acid phosphatase is induced [2]. The leukapheresis and infusion process is repeated approximately every 2 weeks for a total of three doses.

\section{Main text}

Health care providers, consumers, and manufacturers can submit reports of medication errors, adverse events (AEs), and product quality complaints to the Food and Drug Administration Adverse Event Reporting System (FAERS), a national spontaneous reporting system for drug and therapeutic biologics [3]. Medication errors and AEs are coded using terms in the Medical Dictionary for Regulatory Activities (MedDRA) [4]. FDA received a serious FAERS report of a 70-year-old male 
with a history of prostate cancer, hypertension, and diabetes who developed intense pruritus (with no apparent rash) involving the palms, head, torso, and soles of the feet 10 days after the second sipuleucel-T infusion. No other new medications were started before or during the time of receipt of the two sipuleucel-T doses. Treatment for pruritus included daily prednisone $(60 \mathrm{mg})$, cetirizine (30 mg), doxepin $(25 \mathrm{mg})$, and famotidine $(40 \mathrm{mg})$ and as needed cyproheptadine $(4 \mathrm{mg})$. The patient had not experienced symptomatic relief at the time the report was submitted, approximately 6 weeks after the last (second) sipuleucel-T infusion. Additional concomitant medications included dutasteride, flecainide, magnesium oxide, metformin, inhaled mometasone, montelukast, and olmesartan. Sipuleucel-T was discontinued after the second dose. According to the reporter (patient), his oncologist, allergist, and primary care physician attributed the pruritus to sipuleucel- $\mathrm{T}$.

In a recent report of sipuleucel-T and AEs reported to FAERS through December 31, 2017, pruritus was not identified as one of the most commonly reported MedDRA Preferred Terms (PTs), nor was it disproportionately reported (i.e., more than twice expected, a cut-point commonly used by FDA to help assess if further investigation of the drug/biologic-event pair is needed) [5]. To determine if pruritus had been reported previously in association with sipuleucel- $\mathrm{T}$, we searched FAERS for all U.S. reports from April 29, 2010 through December 31, 2018, with sipuleucel-T identified as the primary suspect medication (irrespective of timing of exposure and event) and containing a PT for one of the pruritus terms specified in Table 1 . We conducted Empirical Bayesian data mining analyses using the Multi-Item Gamma Poisson Shrinker algorithm in the Oracle Empirica Signal System to assess for disproportionate reporting of pruritus following sipuleucel-T compared to all other AE-drug/biologic combinations reported to FAERS $[6,7]$.

We identified a total of eight unique reports submitted to FAERS with a pruritus-related PT and sipuleucel-T included as a primary suspect product between April 29, 2010 and December 31, 2018 (Table 1). In addition to the index case noted above, four reports described pruritus and rash occurring within 7 days of sipuleucel-T infusion; two reports described pruritus without rash occurring within 1 day following leukapheresis (prior to sipuleucel-T infusion); and one report did not provide sufficient details to enable temporal assessment. Our data mining analyses did not identify disproportionate reporting for sipuleucel$\mathrm{T}$ and any of the pruritus-related PTs.

\section{Discussion}

Rash is the only dermatologic $\mathrm{AE}$ included in the sipuleucel-T U.S. package insert (USPI) [8]. To our knowledge, pruritus following sipuleucel- $\mathrm{T}$ has not been previously reported in the literature. Pruritus may occur with or without rash. Systemic diseases (e.g., diabetes, hypothyroidism) may be associated with pruritus, and although pruritus is an uncommon paraneoplastic syndrome and is more typically associated with cancers of the lymphohematopoietic system, gastrointestinal and upper respiratory tracts, and (nonmelanoma) skin $[9,10]$, we cannot exclude the possibility that widespread malignancy, diabetes, or another systemic illness may have contributed to pruritus in the index patient. Medications, including GM-CSF, antihypertensives, statins, and others, have been reported to induce pruritus without skin changes [11, 12]. In addition, biologic agents, through their activation of the immune system, can incite cytokine-mediated hypersensitivity reactions, with manifestations overlapping with those of immediate, type I, antibodymediated reactions or can be associated with delayed, type IV cutaneous hypersensitivity reactions that generally occur 7-21 days after exposure [13, 14].

The sipuleucel-T USPI describes acute infusion reactions and other signs and symptoms commonly associated with severe, type I hypersensitivity reactions (e.g., dyspnea, hypotension, tachycardia) [3, 15]. Generalized pruritus (with or without rash) is one of the dermatologic criteria for anaphylaxis and one of the potential symptoms of mucocutaneous, type IV hypersensitivity reactions [14, 15]. A prior FAERS-based sipuleucel-T case series did not identify pruritus as a potential safety signal [5]. However, that report did detect disproportionate reporting of acute infusion reactions, and PTs often associated with these reactions - nausea, hypoxia, tachycardia, presyncope - were also disproportionately reported [5]. Whether as a manifestation of an acute or delayed hypersensitivity reaction, pruritus has been plausibly associated with biologic agents [14] and is a labeled event for some myeloid growth factors [16]. While the role of leukapheresis in pruritus is uncertain, citrate used during leukapheresis may have a potential etiologic role.

FAERS is a large database that is particularly useful for identifying signals for rare AEs. However, it is a passive surveillance system with inherent limitations, including voluntary reporting, underreporting of AEs (e.g., AEs that are not reported, AEs that are not recognized to be associated with a drug/biologic), duplicate reporting, varying report quality with incomplete or missing information, variable reporting of product rechallenge/ dechallenge information, and absence of denominator data $[17,18]$. Therefore, although a causal association between a drug/biologic and an $\mathrm{AE}$ cannot be inferred from FAERS data, this unique resource can aid in the detection of rare or unexpected AEs that may merit further investigation. 
Table 1 Reports of pruritus and sipuleucel-T submitted to the U.S. FDA Adverse Event Reporting System ${ }^{\mathrm{a}}$

\begin{tabular}{|c|c|c|c|c|c|c|c|c|c|c|}
\hline \multirow[b]{2}{*}{$\begin{array}{l}\text { Case } \\
\text { No. }\end{array}$} & \multirow[b]{2}{*}{$\begin{array}{l}\text { Age } \\
\text { (years) }\end{array}$} & \multirow[b]{2}{*}{$\begin{array}{l}\text { Serious } \\
\text { report? }^{b}\end{array}$} & \multirow[b]{2}{*}{$\begin{array}{l}\text { Preferred } \\
\text { Term }^{c}\end{array}$} & \multirow[b]{2}{*}{ Rash } & \multirow[b]{2}{*}{$\begin{array}{l}\text { Clinical } \\
\text { description }\end{array}$} & \multicolumn{3}{|c|}{$\begin{array}{l}\text { Time to onset of symptoms from } \\
\text { leukapheresis or infusion }\end{array}$} & \multirow[b]{2}{*}{ Medical history $^{d}$} & \multirow[b]{2}{*}{$\begin{array}{l}\text { Concomitant } \\
\text { medications }\end{array}$} \\
\hline & & & & & & $\begin{array}{l}\text { Day } \\
\text { No. }\end{array}$ & $\begin{array}{l}\text { Leukapheresis } \\
\text { No. }\end{array}$ & $\begin{array}{l}\text { Infusion } \\
\text { No. }\end{array}$ & & \\
\hline \multicolumn{11}{|c|}{ Reports describing events in temporal association with sipuleucel-T } \\
\hline $1^{e}$ & 70 & Yes & $\begin{array}{l}\text { Pruritus } \\
\text { generalized }\end{array}$ & No & $\begin{array}{l}\text { Itching on palms, head, } \\
\text { torso, and soles of feet }\end{array}$ & 10 & $\sim$ & 2 & $\begin{array}{l}\text { Hypertension, } \\
\text { diabetes }\end{array}$ & $\begin{array}{l}\text { Cetirizine, } \\
\text { cyproheptadine, } \\
\text { doxepin, dutasteride, } \\
\text { famotidine, flecainide, } \\
\text { magnesium oxide, } \\
\text { metformin, } \\
\text { mometasone } \\
\text { (inhaled), montelukast, } \\
\text { olmesartan, } \\
\text { prednisone }\end{array}$ \\
\hline 2 & 69 & No & Pruritus & Yes & $\begin{array}{l}\text { Broke out in a } \\
\text { rash, itching }\end{array}$ & 2 & $\sim$ & 2 & NOS & $\begin{array}{l}\text { Enzalutamide, } \\
\text { metformin, } \\
\text { tocopherol-fish oil }\end{array}$ \\
\hline 3 & 61 & No & Pruritus & Yes & $\begin{array}{l}\text { Tingling and discomfort } \\
\text { in hands, then forearm } \\
\text { rash (looked like red } \\
\text { rings) with facial } \\
\text { swelling; severe itching; } \\
\text { eyelid swelling. Ten } \\
\text { days after infusion was } \\
\text { well except for itching }\end{array}$ & 7 & $\sim$ & 3 & NOS & $\begin{array}{l}\text { Aspirin, calcium, } \\
\text { famotidine, lisinopril, } \\
\text { vitamin D }\end{array}$ \\
\hline 4 & 81 & Yes & Pruritus & Yes & $\begin{array}{l}\text { Rash, itching, rigors, } \\
\text { nausea, chest tightness, } \\
\text { hypotension, vomited } \\
\text { and hypoxic ( } 85 \% \text { ) after } \\
75-80 \% \text { of infusion } \\
\text { administered. Infusion } \\
\text { discontinued. Admitted } \\
\text { to hospital due to lack } \\
\text { of response to medical } \\
\text { therapy }\end{array}$ & 0 & $\sim$ & 1 & $\begin{array}{l}\text { Hypertension, } \\
\text { hypercholesterolemia }\end{array}$ & $\begin{array}{l}\text { Atenolol, calcium/ } \\
\text { cholecalciferol, } \\
\text { citalopram, enalapril, } \\
\text { simvastatin, vitamins }\end{array}$ \\
\hline 5 & 73 & Yes & Pruritus & Yes & $\begin{array}{l}\text { Swelling right upper } \\
\text { arm (superficial } \\
\text { thrombophlebitis), rash } \\
\text { (IV catheter right hand), } \\
\text { itching, tingling, cough, } \\
\text { dyspnea }\end{array}$ & 0 & $\sim$ & 2 & $\begin{array}{l}\text { Deep vein } \\
\text { thrombosis }\end{array}$ & NOS \\
\hline \multicolumn{11}{|c|}{ Reports describing events in temporal association with leukapheresis (preceding sipuleucel-T) } \\
\hline 6 & 82 & No & $\begin{array}{l}\text { Injection } \\
\text { site } \\
\text { pruritus }\end{array}$ & No & $\begin{array}{l}\text { Right arm injection } \\
\text { site itching }\end{array}$ & 1 & 1 & $\sim$ & $\begin{array}{l}\text { Cardiac disorder, } \\
\text { diabetes }\end{array}$ & $\begin{array}{l}\text { Atenolol, furosemide, } \\
\text { levothyroxine }\end{array}$ \\
\hline 7 & 63 & No & $\begin{array}{l}\text { Eye } \\
\text { pruritus }\end{array}$ & No & $\begin{array}{l}\text { Two separate events of } \\
\text { allergic reaction with } \\
\text { watery and itchy eyes } \\
\text { associated with } \\
\text { leukapheresis (tolerated } \\
\text { three infusions without } \\
\text { problem) }\end{array}$ & 0 & 1 and 3 & $\sim$ & NOS & NOS \\
\hline \multicolumn{11}{|c|}{ Report with insufficient information to assess temporal relationship with sipuleucel-T } \\
\hline 8 & 87 & No & $\begin{array}{l}\text { Catheter } \\
\text { site } \\
\text { pruritus }\end{array}$ & No & $\begin{array}{l}\text { Catheter site pruritus; device related } \\
\text { infection }\end{array}$ & NOS & NOS & NOS & NOS & $\begin{array}{l}\text { Aspirin, calcium } \\
\text { carbonate, } \\
\text { denosumab, fiber, } \\
\text { finasteride, } \\
\text { hydrochlorothiazide/ } \\
\text { lisinopril, probiotic }\end{array}$ \\
\hline
\end{tabular}

Abbreviations: IV intravenous, MedDRA Medical Dictionary for Regulatory Activities, NOS not otherwise specified; not applicable

${ }^{a}$ The FAERS database was searched for all U.S. reports of sipuleucel-T submitted between April 29, 2010 (FDA approval date) and December 31,2018 (data-lock point, February 9, 2019). Among the 11 reports identified, three were excluded from this study (two duplicate reports and one report associated with enzalutamide therapy). All cases were reported among males. Two reports (Case no. 2 and 7) were premedicated prior to receiving sipuleucel-T (acetaminophen, diphenhydramine) ${ }^{\mathrm{b}} \mathrm{A}$ report is considered serious if the patient outcome results in death, life-threatening illness, hospitalization or prolongation of existing hospitalization, permanent disability, or birth defect (21 CFR Part 600.80. Post-marketing reporting of adverse

experiences: https://www.ecfr.gov/cgi-bin/text-idx?SID=41533ceac3cc630045810ffe75304c63\&mc=true\&node=se21.7.600_180\&rgn=div8)

'Pruritus-related MedDRA Preferred Terms: administration site pruritus, anal pruritus, application site pruritus, aquagenic pruritus, brachioradial pruritus, catheter site pruritus, cholestatic pruritus, ear pruritus, eye pruritus, eyelids pruritus, gingival pruritus, implant site pruritus, incision site pruritus, infusion site pruritus, injection site pruritus, instillation site pruritus, lip pruritus, medical device site pruritus, nasal pruritus, oral pruritus, pruritus, pruritus allergic, pruritus generalized, pruritus genital, senile pruritus, stoma site pruritus, tongue pruritus, tumor pruritus, uremic pruritus, vaccination site pruritus, vessel puncture site pruritus, vulvovaginal pruritus

${ }^{\mathrm{d}}$ Other than prostate cancer

eIndex case 


\section{Conclusions}

In this case series we describe eight reports of pruritus and sipuleucel-T as reported to FAERS over an 18-year period. Pruritus following sipuleucel-T administration was rarely, but not disproportionately, reported to FAERS. Widespread malignancy, diabetes, and other conditions may have contributed to pruritus in our index case, but in the context of timing of exposure to biologic therapy, particularly one possibly associated with GM-CSF [11, 12], and $\mathrm{AE}$ onset, a drug/biologic-related reaction is plausible. Pruritis may be debilitating among those affected, and in the appropriate clinical setting, sipuleucel-T or its components (e.g., residual GM-CSF) should not be overlooked as having a potentially relevant etiologic role.

\section{Abbreviations}

AE: Adverse event; FAERS: Food and Drug Administration Adverse Event Reporting System; GM-CSF: Granulocyte-macrophage colony-stimulating factor; MedDRA: Medical Dictionary for Regulatory Activities; Mg: Milligram; PT: Preferred Term; SOC: System Organ Class; U.S.: United States; USPI: Unites States Package Insert

\section{Acknowledgements}

The opinions and information in this article are those of the authors, and do not represent the views and/or policies of the U.S. Food and Drug Administration.

\section{Authors' contributions}

GMD: Conceived and designed the study, acquired data, analyzed and interpreted the data, drafted the manuscript, gave approval of the final version submitted for publication and is accountable for all aspects of the work in ensuring that questions related to the accuracy or integrity of any part of the work is appropriately investigated and resolved. SP-V: Designed the study, analyzed and interpreted the data, revised the manuscript for important intellectual content, gave approval of the final version submitted for publication and is accountable for all aspects of the work in ensuring that questions related to the accuracy or integrity of any part of the work is appropriately investigated and resolved. MTN: Designed the study, analyzed and interpreted the data, revised the manuscript for important intellectual content, gave approval of the final version submitted for publication and is accountable for all aspects of the work in ensuring that questions related to the accuracy or integrity of any part of the work is appropriately investigated and resolved.

\section{Funding}

None.

\section{Availability of data and materials}

Refer to Main Text.

\section{Ethics approval and consent to participate}

FAERS is a legally mandated, government-sponsored surveillance system administered by FDA. This safety review is exempt from Institutional Review Board approval or informed consent because it meets criteria for exemption from the Office for Protection from Research Risks as specified in the Code of Federal Regulations: https://www.ecfr.gov/cgi-bin/retrieveECFR?gp=\&SID= 83cd09e1 c0f5c6937cd9d7513160fc3f\&pitd=20180719\&n=pt45.1.46\&r= PART\&ty=HTML\#se45.1.46_1104.

\section{Consent for publication}

Refer to "Ethics and approval and consent to participate" section above.

\section{Competing interests}

The authors declare that they have no competing interests.

\section{Author details}

'Division of Epidemiology, Office of Biostatistics and Epidemiology, Center for Biologics Evaluation and Research, U.S. Food and Drug Administration, 10903 New Hampshire Avenue, Silver Spring, MD 20993-0002, USA. ² Office of Surveillance and Epidemiology, Center for Drug Evaluation and Research, U.S. Food and Drug Administration, 10903 New Hampshire Avenue, Silver Spring, MD 20993-0002, USA.

Received: 29 September 2019 Accepted: 9 December 2019 Published online: 19 December 2019

\section{References}

1. Provenge (sipuleucel-T): Summary basis for regulatory action, 2010. http:// wayback.archive-it.org/7993/20170723023808/https://www.fda.gov/ downloads/BiologicsBloodVaccines/CellularGeneTherapyProducts/ ApprovedProducts/UCM213114.pdf. Last accessed November 11, 2019.

2. Approved Products: Provenge (sipuleucel-T). https://www.fda.gov/ BiologicsBloodVaccines/CellularGeneTherapyProducts/ApprovedProducts/ ucm210012.htm. Last accessed June 17, 2019. Accessed 11/11/2018.

3. US Food and Drug Administration. Questions and Answers on FDA's Adverse Event Reporting System https://www.fda.gov/Drugs/ GuidanceComplianceRegulatoryInformation/Surveillance/ AdverseDrugEffects/ Last accessed November 11, 2019

4. Medical dictionary for regulatory activities. https://www.meddra.org/sites/ default/files/guidance/file/intguide_20_1_english_0.pdf. Last accessed November 11, 2019.

5. Dores GM, Bryant-Genevier M, Perez-Vilar S. Adverse events associated with the use of Sipuleucel-T reported to the US Food and Drug Administration's adverse event reporting system, 2010-2017. JAMA Netw Open. 2019;2(8): e199249. https://doi.org/10.1001/jamanetworkopen.2019.9249.

6. DuMouchel W. Bayesian data mining in large frequency tables, with an application to the FDA spontaneous reporting system. Am Stat. 1999;53:177-90.

7. Szarfman A, Machado SG, O'Neill RT. Use of screening algorithms and computer systems to efficiently signal higher-than-expected combinations of drugs and events in the US FDA's spontaneous reports database. Drug Saf. 2002;25(6):381-92.

8. PROVENGE ${ }^{\oplus}$ (sipuleucel-T) prescribing information. Published July 2017. http://www.provengehcp.com/Portals/5/Provenge-PI.pdf. Last accessed November 11, 2019.

9. Yosipovitch G. Chronic pruritus: a paraneoplastic sign. Dermatol Ther. 2010; 23(6):590-6. https://doi.org/10.1111/j.1529-8019.2010.01366.x.

10. Rowe B, Yosipovitch G. Malignancy-associated pruritus. Eur J Pain. 2016; 20(1):19-23. https://doi.org/10.1002/ejp.760.

11. Cassano N, Tessari G, Vena GA, Girolomoni G. Chronic pruritus in the absence of specific skin disease: an update on pathophysiology, diagnosis, and therapy. Am J Clin Dermatol. 2010;11(6):399-411. https://doi.org/10. 2165/11317620-000000000-00000

12. Reich A, Stander S, Szepietowski JC. Drug-induced pruritus: a review. Acta Derm Venereol. 2009;89(3):236-44. https://doi.org/10.2340/00015555-0650.

13. Picard M, Galvao VR. Current knowledge and Management of Hypersensitivity Reactions to monoclonal antibodies. J Allergy Clin Immunol Pract. 2017:5(3):600-9. https://doi.org/10.1016/j.jaip.2016.12.001.

14. Baldo BA. Adverse events to monoclonal antibodies used for cancer therapy: focus on hypersensitivity responses. Oncoimmunology. 2013;2(10): e26333. https://doi.org/10.4161/onci.26333.

15. Ruggeberg JU, Gold MS, Bayas JM, Blum MD, Bonhoeffer J, Friedlander S, et al. Anaphylaxis: case definition and guidelines for data collection, analysis, and presentation of immunization safety data. Vaccine. 2007;25(31):5675-84. https://doi.org/10.1016/j.vaccine.2007.02.064

16. DailyMed. https://dailymed.nlm.nih.gov. Last accessed November 11, 2019.

17. Alatawi YM, Hansen RA. Empirical estimation of under-reporting in the U.S. Food and Drug Administration adverse event reporting system (FAERS). Expert Opin Drug Saf. 2017;16(7):761-7. https://doi.org/10.1080/14740338. 2017.1323867

18. Alvarez-Requejo A, Carvajal A, Begaud B, Moride Y, Vega T, Arias LH. Underreporting of adverse drug reactions. Estimate based on a spontaneous reporting scheme and a sentinel system. Eur J Clin Pharmacol. 1998;54(6):483-8.

\section{Publisher's Note}

Springer Nature remains neutral with regard to jurisdictional claims in published maps and institutional affiliations. 